\title{
Beta Thromboglobulin and Alcohol Consumption
}

\author{
Lt Col P J Gravett \\ MRCPath, RAMC
}

W01 S J Milligan

FIMLS, LIBiol, RAMC

The John Boyd Laboratory, Queen Elizabeth Military

Hospital, Woolwich

SUMMARY: Beta Thromboglobulin plasma levels were measured in three groups of hospital patients; a contro $\overrightarrow{\mathrm{P}}$ group $(n=13)$ of non-drinkers, and test groups of patients who from their medical history regularly consumed either moderate amounts $(80-200 G / 24$ hours $n=31)$ or large amounts $(200 G / 24$ hours $n=10)$ of alcohol Significant differences were detected between the control group, and both groups of drinkers. A correlation waș demonstrated between the amount of alcohol consumed and the plasma Beta Thromboglobulin.

It is necessary to consider a patient's drinking habits when interpreting Beta Thromboglobulin levels.

\section{Introduction}

Beta Thromboglobulin (Beta TG) is a platelet specific protein ${ }^{1}$ whose plasma concentration reflects intravascular platelet aggregation and release ${ }^{2}$. Elevated levels have been described in such conditions as deep-vein thrombosis ${ }^{3}$, diabetic microangiopathy ${ }^{4}$, and myeloproliferative disorders ${ }^{\tilde{5}}$. It has been suggested that the measurement of Beta TG is a useful index of in vivo platelet activation ${ }^{6}$ which may correlate with thrombus formation, particularly in the microcirculation, and be of use in the diagnosis of thromboembolic disorders ${ }^{3}$.

The ingestion of alcohol impairs the platelet release reaction and leads to reduced platelet survival. Thrombocytopenia may supervene if the marrow is unable to compensate for the reduced platelet life span by an adequate increase in effective thrombopoiesis ${ }^{7}$. Even when a normal platelet count is maintained there is an increased platelet turnover of ATP, possibly indicating an increased energy requirement for the repair of ethanol induced cell damage ${ }^{8}$. In this situation an increase in circulating platelet release products might occur which would be reflected in an elevated plasma level of Beta TG. In this paper we describe the investigation of blood platelets and plasma levels of Beta TG in non-alcoholic and alcoholic patients.

\section{Patients and Methods}

Male patients admitted to a General Medical Ward were asked for details of their drinking habits as part of the routine history taken at initial assessment. Those patients with a moderate alcohol consumption ( $80-200 \mathrm{G} / 24$ hours) formed one test group, and those with a heavy alcohol consumption ( $>200 \mathrm{G} / 24$ hours) formed the second test group, most of whom had been admitted specifically for then treatment of their alcohol abuse. Patients wh్t claimed a zero alcohol consumption formed the cofh-은 trol group.

Patients suffering from any condition which mightc exacerbate intravsacular platelet release were elimin ted from the study.

Control and experimental group patients underw venepuncture as soon as possible after admission uुs $\overrightarrow{0}$ ing a polypropylene syringe fitted with a 19 gause needle. Particular attention was paid to the sampling conditions, ensuring that a maximum of $10 \mathrm{mls}$, blood was taken without venous stasis and a two millilitre aliquot dispensed into a pre-cooled tube@ containing anticoagulant and antiplatelet reagent with $-\frac{\mathrm{Q}}{\mathrm{D}}$ in three minutes of venepuncture ${ }^{9}$. The sample tubes were transmitted to the laboratory in a mixture ofo crushed ice and water, separation of the plasma carried out in a refrigerated centrifuge within one hour of venepuncture, and the samples frozen at $-20^{\circ} \mathrm{C}$ for up to four weeks before processing.

Cell counts were performed on a "Sequestrene" blood sample within two hours of venepuncture using a Coulter ZF6 system (Coulter Electronics Ltd, Har- $-\bar{\Phi}$ penden, Herts) to measure the red cell parameters, and the method of Dacie and Lewis ${ }^{10}$ for the whole -5 blood platelet count using ammonium oxalate as 3 . diluent and an "Improved Neubauer" counting cham-i ber.

Beta TG was measured by radioimmunoassay, using ${ }^{125}$ iodine labelled Beta TG in a modification of the protocol of Ludlam and Cash $^{9}$, in accordance $\frac{D}{O}$ with the instructions issued by the Radiochemical Centre, Amersham, for use with their assay kit.N Counting was performed with an automatic gamman scintillation counter (MSC 120D, J \& P Engineering N (Reading) Lid). 
Table 1

Results of Platelet Counts and Beta Thromboglobulin Assays for Control and Test Groups

\begin{tabular}{|c|c|c|c|c|}
\hline No & Diagnosis & $\begin{array}{l}\text { Alcohol } \\
\text { G24hrs }\end{array}$ & $\begin{array}{l}\text { Platelets } \\
\text { x } 109 / 1\end{array}$ & $\begin{array}{r}\text { BTG } \\
\mathrm{ng} / \mathrm{ml}\end{array}$ \\
\hline \multicolumn{5}{|c|}{ GROUP ONE-ZERO } \\
\hline 1 & Viral Inf & & 139 & 24 \\
\hline 2 & Drop Attacks & & 263 & 16 \\
\hline 3 & Hypertension & & 161 & 24 \\
\hline 4 & Reiter's Synd & & 180 & 17 \\
\hline 5 & Viral Inf & & 207 & 54 \\
\hline 6 & Abdo pain & & 197 & 30 \\
\hline 7 & Influenza & & 134 & 32 \\
\hline 8 & Bronchitis & & 298 & 21 \\
\hline 9 & Ulnar Palsy & & 289 & 18 \\
\hline 10 & Obesity & & 143 & 19 \\
\hline 11 & Eczema & & 131 & 56 \\
\hline 12 & Headaches & & 184 & 10 \\
\hline 13 & Orchitis & & 259 & 27 \\
\hline
\end{tabular}

\section{GROUP TWO-MODERATE}

\begin{tabular}{|c|c|c|c|c|}
\hline 14 & Hepatitis & 80 & 110 & 26 \\
\hline 15 & Chest Pain & 100 & 283 & 16 \\
\hline 16 & Grand Mal & 200 & 239 & 36 \\
\hline 17 & Hypertension & 120 & 190 & 46 \\
\hline 18 & Gastritis & 160 & 255 & 74 \\
\hline 19 & Gonorrhoea & 60 & 142 & 86 \\
\hline 20 & Spherocytosis & 100 & 277 & 68 \\
\hline 21 & Viral Inf & 80 & 243 & 56 \\
\hline 22 & Alcohol Abuse & 160 & 147 & 58 \\
\hline 23 & Obesity & 60 & 194 & 21 \\
\hline 24 & Ulcerative Colitis & 80 & 161 & 100 \\
\hline 25 & Chest Inf & 140 & 177 & 17 \\
\hline 26 & Gastritis & 100 & 176 & 60 \\
\hline 27 & Obesity & 20 & 277 & 18 \\
\hline 28 & Alcohol Abuse & 100 & 283 & 68 \\
\hline 29 & Alcohol Abuse & 160 & 226 & 16 \\
\hline 30 & Alcohol Abuse & 140 & 288 & 66 \\
\hline 31 & Alcohol Abuse & 190 & 173 & 50 \\
\hline 32 & Alcohol Abuse & 170 & 175 & 48 \\
\hline 33 & Alcohol Abuse & 200 & 230 & 22 \\
\hline 34 & Alcohol Abuse & 100 & 231 & 68 \\
\hline 35 & Obesity & 80 & 107 & 26 \\
\hline 36 & Alcohol Abuse & 120 & 180 & 42 \\
\hline 37 & Alcohol Abuse & 160 & 175 & 34 \\
\hline 38 & Alcohol Abuse & 90 & 237 & 100 \\
\hline 39 & Eczema & 120 & 394 & 41 \\
\hline 40 & Alcohol Abuse & 200 & 288 & 62 \\
\hline 41 & Alcohol Abuse & 120 & 237 & 76 \\
\hline 42 & Obesity & 80 & 187 & 91 \\
\hline 43 & Obesity & 80 & 210 & 111 \\
\hline 44 & Ulnar Palsy & 80 & 174 & 35 \\
\hline
\end{tabular}

\section{GROUP THREE-HEAVY}

\begin{tabular}{llllr}
45 & Gastro Enteritis & 300 & 150 & 64 \\
46 & Alcohol Abuse & 400 & 147 & 102 \\
47 & Epilepsy & 274 & 183 & 88 \\
48 & Alcohol Abuse & 480 & 133 & 102 \\
49 & Alcohol Abuse & 284 & 183 & 36 \\
50 & Alcohol Abuse & 400 & 239 & 146 \\
51 & Alcohol Abuse & 300 & 251 & 220 \\
52 & Alcohol Abuse & 360 & 179 & 44 \\
53 & Alcohol Abuse & 240 & 222 & 28 \\
54 & Alcohol Abuse & 240 & 234 & 119 \\
\hline
\end{tabular}

\section{Results}

The Beta TG assay showed a coefficient of variation within batch of $3.4 \%$ and between batches of $10.52 \%$. The results for the control group $(26.8 \mathrm{ng} / \mathrm{ml}$ with a standard deviation of $\pm 13.9 \mathrm{ng} / \mathrm{ml}$ ) coincide well with the previously published normal range of $10-65 \mathrm{ng} / \mathrm{ml}^{1}$.

The results of platelet counts and Beta TG assays N are given in Table $I$, and a comparison of these results between patient groups, using the dependen@ and independent ' $t$ ' statistics is presented in Table II. Although there are no significant differences in platelet counts between the groups, and no patient迎 even in the heavy drinking group, was thrombocyto巴 penic, differences in Beta TG levels are noted betweeß all groups. This difference is especially marked $\overrightarrow{0}$ $(P<0.025)$ between the control and heavy drinking $\$$ groups, and a correlation was demonstrated (Fig 1). $(\mathrm{r}=0.39 ; 0.05<\mathrm{p}<0.01)$ between alcohol cono sumption and Beta TG for both drinking groups.

\section{Discussion}

The prevalence of alcoholism amongst people admitted to hospital is six times greater than in the general population ${ }^{1}$.

Excessive alcohol consumption causes an increase in total thrombopoiesis and megakaryocyte mass with reduced platelet survival, and thrombocytopenia when the marrow cannot compensate effectively ${ }^{7}$. Elevated levels of circulating platelet release products might thus be detected in heavy drinkers and hence a proportion of hospital patients might show unexpectedly high plasma Beta TG levels.

This study demonstrates significant differences in Beta TG levels between the non-drinking control group and both groups of drinkers. The correlation 응 demonstrated between the platelet count and the $D$ Beta TG level has been described previously both in normal patients and in those with myeloproliferative disorders and secondary thrombocytosis ${ }^{5}$, but there $\sigma$ was also a significant correlation of Beta TG with the $\mathcal{N}$ amount of alcohol consumed $(0.05>p>0.01)$. 
Table II

Analysis of Platelet Count and Beta Thromboglobulin Assay Results

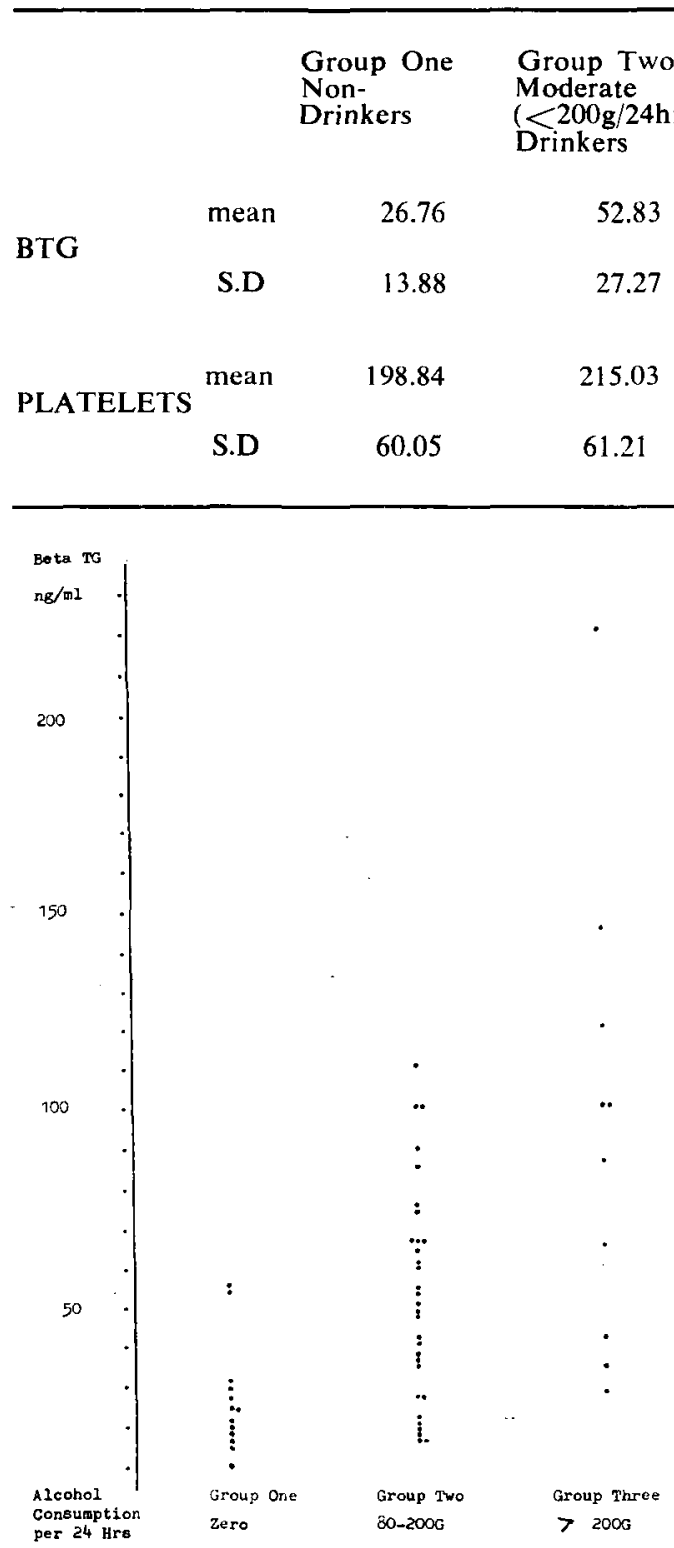

Fig. 1 Beta Thromboglobulin Level. Distribution in the three patient groups

We conclude that excessive alcohol consumption has a significant effect on the level of circulating platelet release products. When employing any diagnostic procedure every effort must be made to minimize the

incidence of both false positive and false negative results; it is thus important to consider a patien's alcohol intake when attempting to interpret a be्gfa thromboglobulin level as a direct index of plateforo activation in the investigation of thromboembotix.disorders.

\section{REFERENCES}

1 Ludlam, C A Evidence for the Platelet Specificits of Beta Thromboglobulin and Studies on its Plasplap Concentration in Healthy Individuals. $\mathrm{Br}$ J. Haemsa tol 1979; 41: 271-278.

2 YaO-ChANG, Chen and $\mathrm{K}$ Wu. A Comparison Methods for the Study of Platelet Hyperfunction in Thromboembolic Disorders Br J Haematol 1980; 46: $263-268$.

3 LudLAm, C A et al. New Rapid Method for Diagno尺 sis of Deep Vein Thrombosis Lancet 1975;2 2 259-260.

4 Preston, F E et al. Elevated Beta Thromboglobulin levels and Circulating Platelet Aggregates in Diabe tic Microangiopathy. Lancet EFSBH 1: 238-239?

5 Boughton, B J, Allington, M J and King, A. Plate let and Plasma Beta Thromboglobulin in Myeloproli ferative Syndromes and Secondary Thrombocytosis Br J Haematol 1978; 40: 125-132.

6 Cella, G et al. Beta Thromboglobulin, Platelet Pro duction Time and Platelet Function in Vascular Dis ease $\mathrm{Br}$ J. Haematol 1979; 43: 127-136.

7 Cowan, D H. Thrombokinetic studies in Alcoholrelated Thrombocytopenia J Lab Clin Med 1973; 812. 64-76.

8 Cowan, D H and Graham R C Jr. Studies on the Platelet Defect in Alcoholism Thromb Diathes Haemorrh (Stultg) 1975; 33: 310.

9 Ludlam, C A and Cash, J D Studies on the Libera $\rightarrow$ tion of Beta Thromboglobulin from Human Platelets. in Vitro Br J Haematol 1976; 33: 239.

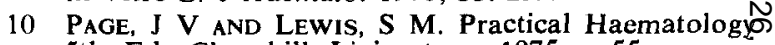
5th Ed. Churchill Livingstone 1975 pp55.

11 Jarman, C M B and Kelletr, J M. Alcoholism in the General Hospital $\mathrm{Br}$ Med J 1979; 2: 469-472 